\title{
Hybrid Solar-RF Energy Harvesting Systems for Electric Operated Wheelchairs
}

\author{
Cuong V. Nguyen ${ }^{1}$, Minh T. Nguyen ${ }^{2}{ }^{-1}$, Toan V. Quyen ${ }^{2,3}$, Anh M. Le ${ }^{2,4}$, \\ Antonino Masaracchia ${ }^{5, *}$, Ha T. Nguyen ${ }^{6}$, Huy P. Nguyen ${ }^{2}$, Long D. Nguyen ${ }^{1}$, \\ Hoa T. Nguyen ${ }^{2}$ and Vinh Q. Nguyen ${ }^{7}$ (1) \\ 1 Institute of Research and Development, Duy Tan University, Danang 550000, Vietnam; \\ nguyenvancuong18@duytan.edu.vn (C.V.N.); dinhlonghcmut@gmail.com (L.D.N.) \\ 2 Department of Electrical Engineering, Thai Nguyen University of Technology, Thai Nguyen 24131, Vietnam; \\ nguyentuanminh@tnut.edu.vn (M.T.N.); quyenvantoan.tnut@gmail.com (T.V.Q.); \\ lemyanh2612@gmail.com (A.M.L.); nguyenphuonghuy@tnut.edu.vn (H.P.N.); \\ nguyenthituyethoa@tnut.edu.vn (H.T.N.) \\ 3 School of Electronics Engineering, Kyungpook National University, Daehakro 80, Daegu 41566, Korea \\ 4 College of Electrical and Computer Engineering, National Chiao Tung University, Hsinchu 30010, Taiwan \\ 5 School of Electronics, Electrical Engineering and Computer Science, Queen's University Belfast, \\ Belfast BT3 9DT, UK \\ 6 Department of Electronics Engineering, Thai Nguyen University, Thai Nguyen 24118, Vietnam; \\ hant@tnu.edu.vn \\ 7 Department of Electronics and Radio Engineering, Academy of Military Science and Technology, \\ Hanoi 122100, Vietnam; vinhquang2808@yahoo.com \\ * Correspondence: A.Masaracchia@qub.ac.uk; Tel.: +44-774-524-4722
}

Received: 13 March 2020; Accepted: 29 April 2020; Published: 2 May 2020

\begin{abstract}
Over the decades, with the advancement of science and technology, wheelchairs have undergone remarkable changes, such as controlling an electrical wheelchair by using brain signals. However, existing electrical wheelchairs still need improvements in terms of energy management. This paper proposes an hybrid Solar-Radio frequency (RF) harvesting system able to supply power for the continuous and effective operation of electrically powered wheelchairs. This system can simultaneously harvest power from RF and solar source that are both available in the surrounding environment. A maximum power point tracking (MPPT) and a boost converter are exclusively employed for the standalone solar system while the standalone RF system is equipped with a 9-stage voltage multiplier (VM). The voltage level for the charging process is obtained by adding the output voltage of each source. In addition, a current booster and a stabilizer are used to reach the required level of current and pin the charging voltage to a stable level, respectively. Simulation results show how the hybrid system is better and more stable when the boost current and stabilizer are used in the charging system. Moreover, we also provide some analytic results to prove the advantages of this system.
\end{abstract}

Keywords: solar cells; RF energy harvesting; hybrid energy harvesting; rechargeable batteries; electric wheelchairs

\section{Introduction}

Wheelchairs represent one of the most common assistive devices that permit to improve the quality of life of people with limited mobility problems, such as disabled persons and elderly, by offering them autonomous mobility opportunities. The first wheelchair model, also known as invalid's chair, was the one made for Philip II of Spain at the end of 16th century [1]. From that starting point, the concept 
of this assistive device started to evolve trying to address needs and circumstances of their users from time to time [2]. According to their propulsion system, wheelchairs can be categorized in two main classes: (i) manually powered wheelchair (MW), and (ii) electrically powered wheelchair (EW). The MW is the most commonly seen wheelchair in the hospital. However, this is not the optimal choice for elderly persons and both legs and arm disabled persons, which could not have the sufficient strength to propel themselves. On the other hand, EWs offer a completely different approach, enabling users to control and navigate their wheelchair independently using a traditional joystick or alternative control systems, such as head joysticks, chin joysticks, sip-n-puff, and thought control [3-7]. Therefore, EW can be labelled as the best option at an affordable price.

Basically, the main components of an EW are: (i) a chassis, which can be foldable and can have different abilities, such as stair-climbing or standing positions, (ii) a controller, which is the interface between human and machine, (iii) a seating system with footrests, lateral supports and backrests, which typically include cushions that use foam, gel, or air to prevent pressure sores, and (iv) a battery unit used to provide energy to the navigation and locomotion system [8]. Although several studies have been conducted to propose innovative solutions to improve ergonomics of chassis and facility of controlling and operating system, addressing different users needs [9-18], the autonomy of EW's users results still strongly dependent on battery lifetime. Indeed, depending on the operating environment and the weight of users, a frequent recharging process for EW's battery may be necessary $[19,20]$, limiting the travelling distance especially into outdoor environments. Moreover, increasing the size of battery embedded into EWs does not represent an optimal solution since to an increase of the size correspond an increase of the weight, which will hinder the movement of the EW.

An alternative solution to the increase of battery size is represented by the design of an hybrid EW with different energy sources. Authors in [21] proposed a model of electrical robotic wheelchair with three energy sources, i.e., a battery, a photovoltaic solar cell, and a hydrogen $\mathrm{f}$ cell. Then, when conditions allow for abundant sunlight, the photovoltaic solar cell is used. When solar energy is not available, the fuel cell is used. Finally, when the hydrogen is depleted, the battery is used. A similar approach has been proposed in [22] where the battery is removed and only photovoltaic and hydrogen cell fuel were used. Then, these approaches enable users to enjoy more independence, especially when they are outdoors. However, even if the sunlight represents an infinite source of energy, these hybrid EWs remains still strongly dependent on a recharging procedure for either battery or hydrogen fuel cell.

Recently, the concept of wireless power transfer (WPT) represents an emerging technology able to provide power to battery constrained devices, such as unmanned aerial vehicles (UAVs) or into wireless sensor networks (WSNs), where the use of electric cables results infeasible [23,24]. Then, a WPT-based approach is able to avoid the dependence of having a charging socket. From these perspectives, this paper proposes a new energy solution for EW's battery charging by combining two sources of infinite energy as solar and RF energy. This mechanism allows EW to charge the battery itself by converting energy from the surrounding environment into power, especially in outdoor environment. In particular, this paper propose an hybrid Solar-Radio frequency harvesting system to supply power for the continuous and effective operating of an electric operated wheelchair.

The rest of the paper is organized as follows. An overview of the proposed system will be described in Section 2. Section 3 describes and discusses the theoretical basis of both standalone solar and RF-based charging system, including respective system diagrams. Section 4 introduce the whole proposed EW's charging solution, presenting and discussing the simulation results subsequently in Section 5. Finally, conclusions and future directions will be presented in Section 6.

\section{System Model}

As outlined before, the power supply for EW are batteries that are charged through the electrical grid either at home or using a dedicated socket. To minimize this dependence and increase flexibility for charging, our system model consists of an hybrid Solar-RF energy harvesting system able to charge EW's batteries. The most used source of energy for harvesting is solar energy. It is renewable 
energy causing pollution-free environment and safer than using traditional electricity. In addition, due to the high life of solar panels, no high level of maintenance is required. In contrast to solar energy that operates during the day, RF energy can be harvested even at night. Indeed, presently, telecommunications technologies are developing rapidly in order to meet smart cities requirements. This leads to the existence of many radio frequencies from base stations, mobile phones, WIFI signals. Then, using energy source from radio frequencies represents a good option. Hence, the combination of RF and solar energy can certainly support each other to create a stable, continuous and efficient source of energy for EW's batteries [25].

The whole system model for the operated wheelchair is illustrated in Figure 1. The solar panels, attached to the top of the wheelchair, are not only used to harvest energy from sunlight but also protect the user from rainy and sunny weather conditions, acting then as a shielding umbrella. In addition, an antenna system is installed in order to harvest RF energy from the surrounding source. The output of these energy sources will be handled through a stabilizer and a current boost system to provide the proper levels of current and voltage to battery. In this paper, we suppose that the EW is equipped with $350 \mathrm{~W}$ motor power that takes energy from a Li-polymer 22.8 V $10 \mathrm{C}$ 6S1P 32,000 mAh battery [26], which has a $22.8 \mathrm{~V}$ discharge voltage and a maximum discharge current of $320 \mathrm{~A}$.

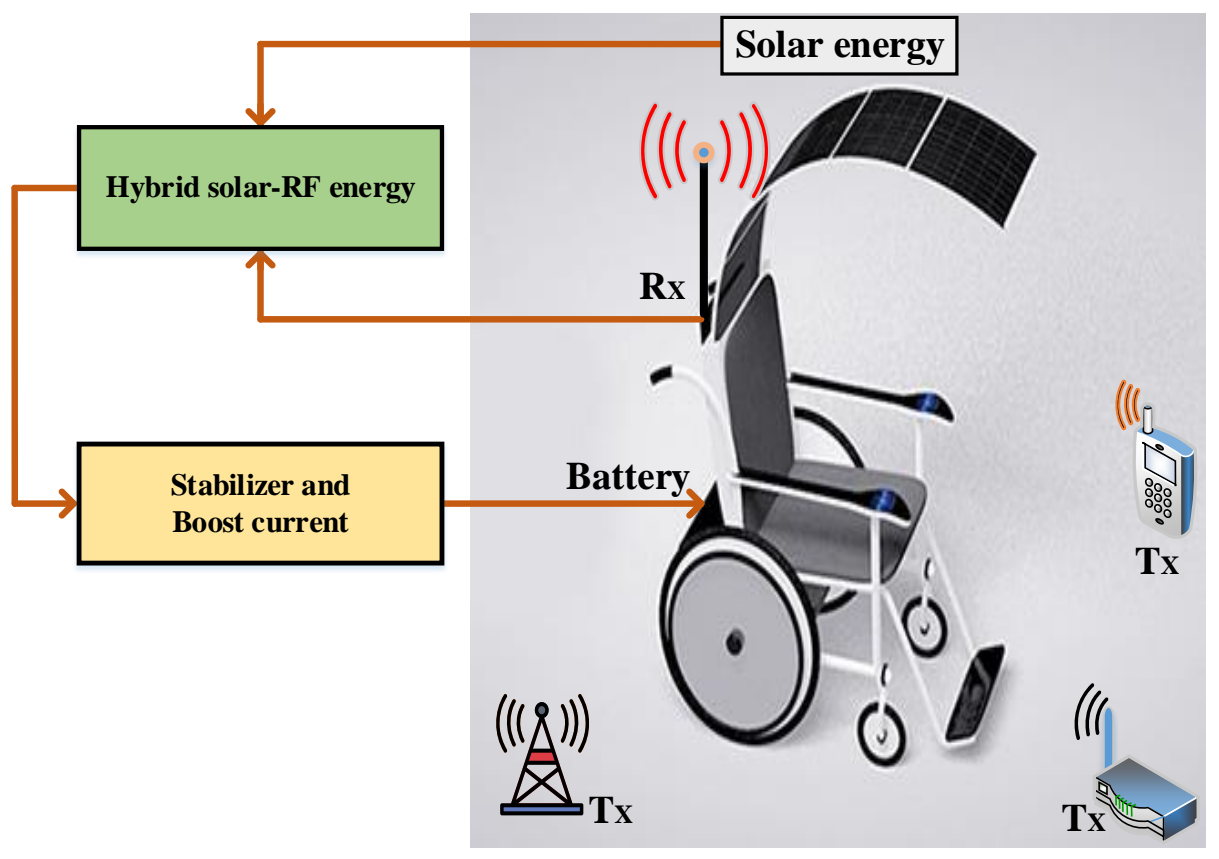

Figure 1. The block diagram of model system for brain operated wheelchair.

Since the charging process is strongly dependent on the charging voltage and current, the output values from the hybrid system cannot be directly used to supply the load, i.e., the battery. Indeed, the charging voltage requires being approximately the rated voltage of the battery while the charging current directly impacts the charging time. Then, they affect significantly the charging process. Our system model uses a stabilizer and a boost current system to modify outputs of the hybrid system before charging the wheelchair's battery.

\section{The Hybrid Solar-Rf Harvesting Energy System}

As illustrated in Figure 2, the proposed system for EW's battery charging can be divided in two main modules, i.e., solar module and RF module, which will be discussed in detail in Sections 3.1 and 3.2 , respectively . 


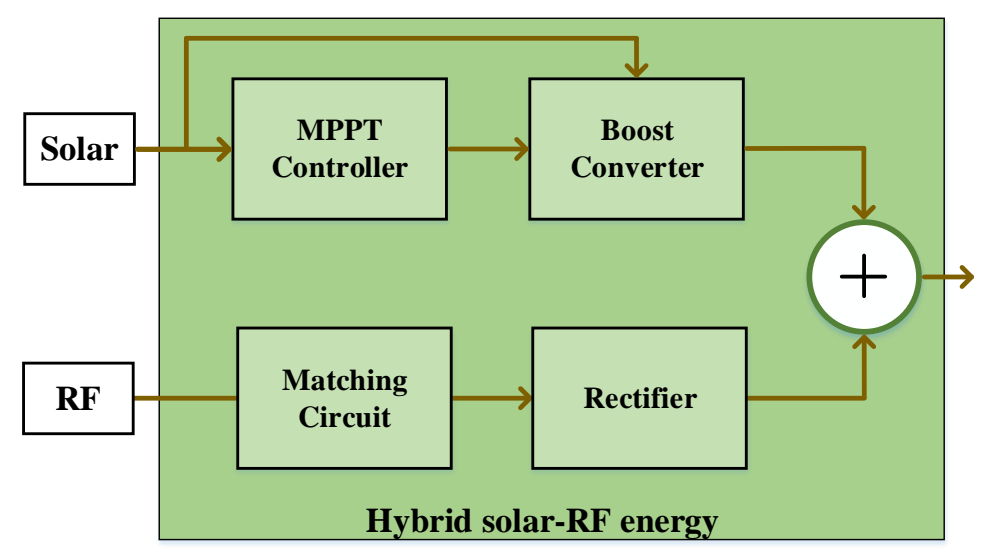

Figure 2. The block diagram of hybrid solar-RF energy system.

\subsection{Solar Energy Module}

The solar system comprises three main parts such as solar panels, MPPT controller, and boost converter. Solar panels are used to extract power from the sunlight by using semiconducting materials. The MPPT controller improves the conversion efficiency and prevents overcharging for battery and unnecessary discharge scenarios. The boost converter steps up the low DC harvesting voltage level to a high DC voltage level in order to meet battery power demand.

Usually, the conversion efficiency from solar arrays into electric energy is low and not suitable for the specific battery charging purpose. To achieve higher efficiency, the MPPT is installed in the solar system. As illustrated in Figure 3, the MPPT tracks the highest power point for the photovoltaic panels, providing the most optimal amount of energy from the solar array to the battery bank by accommodating for differences in voltages between the solar array and the battery bank. The MPPT can monitor the capacity of the batteries and then match the necessary voltage needed from the solar array. Based on potential difference theory, the higher voltage flows to the lower voltage between two points in an electric circuit, which in this paper is the difference between the solar array and the battery bank. During sunny condition, harvesting voltage from the solar panels transfers into the battery. However, in the opposite cases, the power of the battery could be discharged back to the solar arrays. In this case, the MPPT works as a switch, switching off when the solar voltage is lower than the battery voltage. The MPPT is able to tackle this issue by preventing unnecessarily discharging voltage scenario. Moreover, the MPPT also prevents the overcharging by regulating the amount of the amps and current that comes from solar panels to the battery bank.

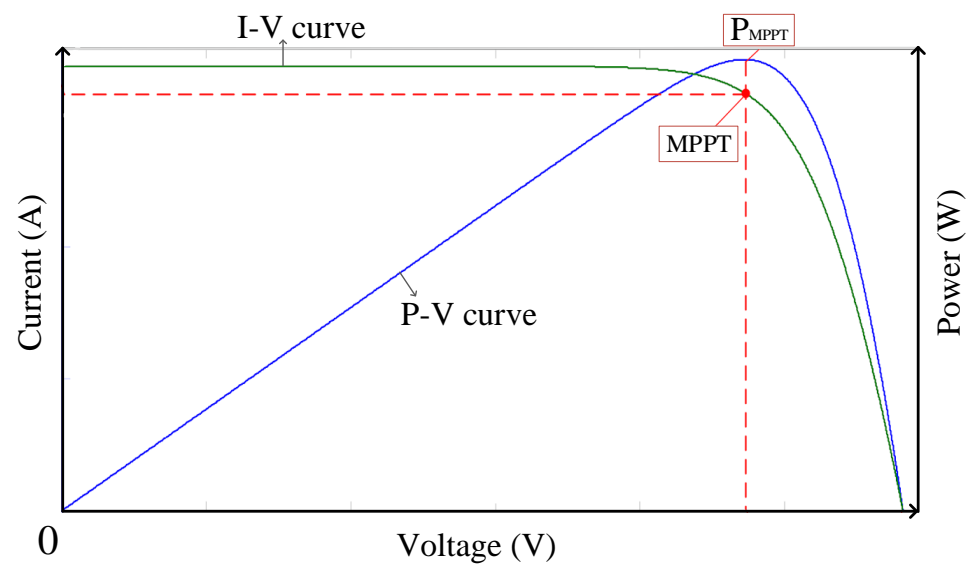

Figure 3. Characteristic curves of a typical PV module. 
The DC-DC boost converter is used to step up a lower DC voltage, generated by solar panels, to higher DC voltage demanded by the wheelchair's battery. Figure 4 depicts the working principle of the boost converter. When the mosfet transistor is ON (Figure 4a), the current from the source only flows through the inductor and the mosfet, and is isolated with the load by the reverse bias of the diode, so the inductor store whole input source during this period. During the OFF state of the switch (Figure $4 \mathrm{~b}$ ), the input source flows through the inductor and the diode to the load. Then, the output voltage $\left(V_{O}\right)$ of DC-DC boost converter is much greater than the input voltage $\left(V_{S}\right)$. Equation (1) shows the relationship between the output voltage and the source [27]:

$$
V_{O}=V_{L}+V_{S}
$$

where $V_{O}$ is the output voltage of the boost converter, $V_{L}$ is the inductor voltage storing during the ON state of mosfet, and $V_{S}$ is the harvesting voltage from the solar arrays. Equation (2) expresses the relationship between the ON and OFF modes of the mosfet switch, where $D_{o n}$ is the ON percentage time of the mosfet transistor and $D_{o f f}$ is the OFF percentage of time of the transistor.

$$
D_{o f f}=1-D_{o n}
$$

On the other side, Equation (3) shows the direct affect of the ON and OFF time of the mosfet transistor to the output voltage, where $V_{s}$ is the source voltage and $V_{O}$ is the output voltage of the boost converter [28].

$$
V_{O}=\frac{V_{S}}{D_{o f f}}
$$

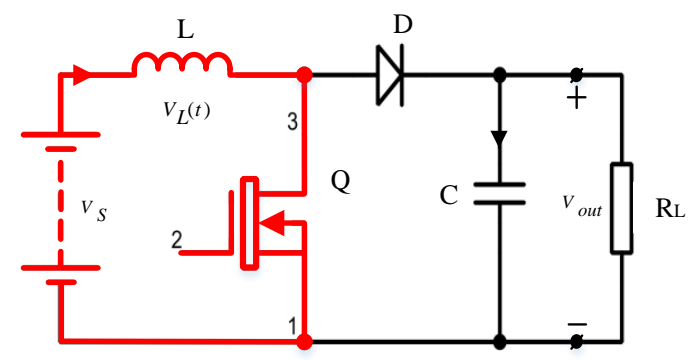

(a) MOSFET ON

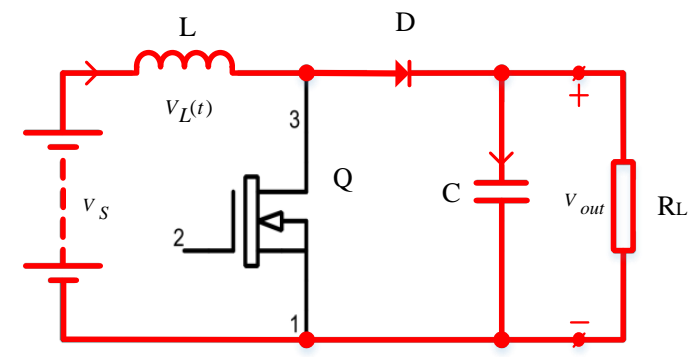

(b) MOSFET OFF

Figure 4. The MOSFET states of the boost converter.

Then, by using the boost converter the output values are able to step up to higher levels. Details about the passive elements used in the boost converter and the dimension of the solar panel are reported in Table 1.

Table 1. The information of solar panel and passive elements for the boost converter.

\begin{tabular}{ccccccc}
\hline Parameters & Solar Panel & Inductor & Mosfet & Capacitor & Resistor & Diode \\
\hline Value & $121.7 \times 53.3 \times 0.2 \mathrm{~cm}-1.8 \mathrm{~kg}$ & $3 \mathrm{mH}$ & IRF540N & $100 \mu \mathrm{F}$ & $6.6 \Omega$ & $1 \mathrm{~N} 4007$ \\
\hline
\end{tabular}

However, even if it is higher than the input source, the output voltage of such boost converter can fluctuate and then may be not suitable for charging the battery.

\subsection{Radio Frequency Energy}

As illustrated in Figure 5, the RF harvesting energy circuit comprises a receiving antenna, a matching circuit and a rectifier circuit . 


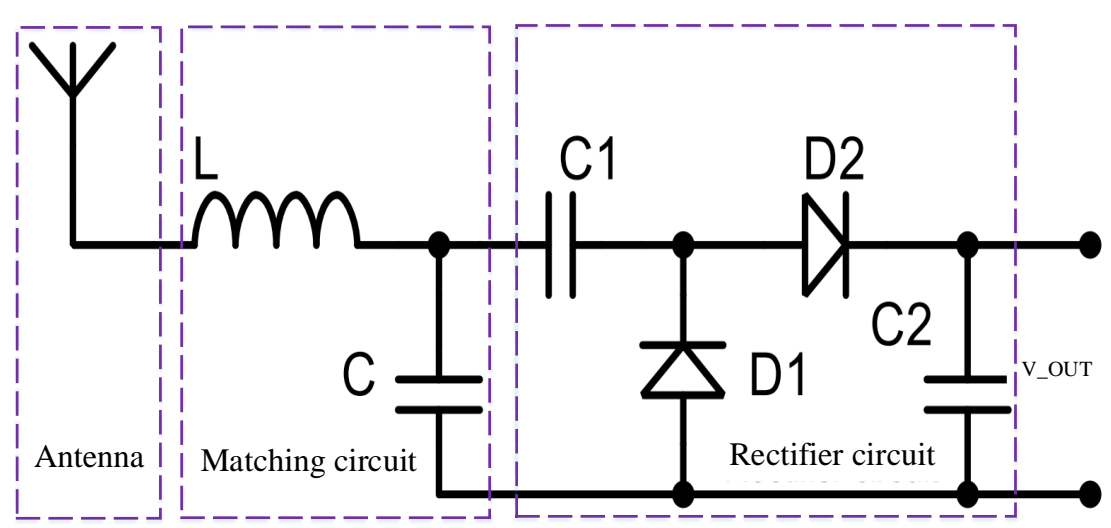

Figure 5. The principle of harvesting RF energy system.

The antenna harvest energy from electromagnetic waves, converting it into electrical energy. Depending on their designs, antennas can capture different frequency ranges in the environment. The popular RF bands are TV broadcast (500-700 MHz), mobile phones (900 MHz), local area networks (2.4-5.8 GHz), Wi-Fi signals (5 GHz), satellite stations (1-40 GHz), radar (5 MHZ-130 GHz). The amount of power captured by a generic receiving antenna can be expressed as [29]:

$$
P_{\text {antenna }}=G \times L_{c} \times P_{t} \times G_{t}\left(\frac{\lambda}{4 \pi d}\right)
$$

where $P_{\text {antenna }}$ is the output power at the antenna, $G$ is the receiving gain, $L_{c}$ is the loss factor, $P_{t}$ is the transmitting power, $G_{t}$ the transmitting gain, $\lambda$ is the wavelength, $d$ is the distance between transmitter and the antenna. To improve the transferring performance between the antenna and the rectifier circuit (voltage multiplier), the RF harvesting system must employ a matching circuit which consists of one coil and one capacitor. The matching circuit matches antenna's impedance with proper impedance of the voltage multiplier (VM) enhancing transmission efficiency. The VM is a multi-stage circuit that includes two diodes and two capacitors in each stage. It is used to convert the AC harvesting voltage of the antenna to the DC voltage, boosting it to higher values. With the same input voltage, the more numbers of the VM's stages is employed, the higher output voltage can be approached. In particular, output voltage for an $\mathrm{N}$-stage with the ideal voltage multiplier is [30]:

$$
U_{\text {OUT }}=4 \times N \times U_{I N}
$$

where $U_{O U T}$ is the output voltage of the $\mathrm{VM}, \mathrm{N}$ is the number stages, and $U_{I N}$ is the input voltage of the voltage multiplier. In Figure 6, we show and compare some different stage numbers of VM. Depending on both the output value and the settling time, in this paper we suppose to use the nine stages VM to meet power for hybrid system. The simulating model of the VM to amplify the RF harvesting power is illustrated in Figure 7.

Table 2 contains some information of the common RF source and also detail about some passive elements of the employed VM system.

\begin{tabular}{|c|c|c|c|c|c|}
\hline \multirow{2}{*}{ Parameter } & \multicolumn{2}{|c|}{ RF Signal } & \multirow{2}{*}{ Inductor } & \multirow{2}{*}{ Capacitor } & \multirow{2}{*}{ Diode } \\
\hline & Frequency & Amplitude & & & \\
\hline Value & $\begin{array}{c}900 \mathrm{MHz} \\
2.4 \mathrm{GHz}, 5.8 \mathrm{GHz}\end{array}$ & $0.2 \mathrm{~V}$ & $1 \mathrm{mH}$ & $\begin{array}{c}\mathrm{C}=0.22 \mu \mathrm{F} \\
\mathrm{C}_{1} \text { to } \mathrm{C}_{1} 8=100 \mu \mathrm{F}\end{array}$ & 10DQ015 \\
\hline
\end{tabular}

Table 2. The information of RF harvesting energy system. 


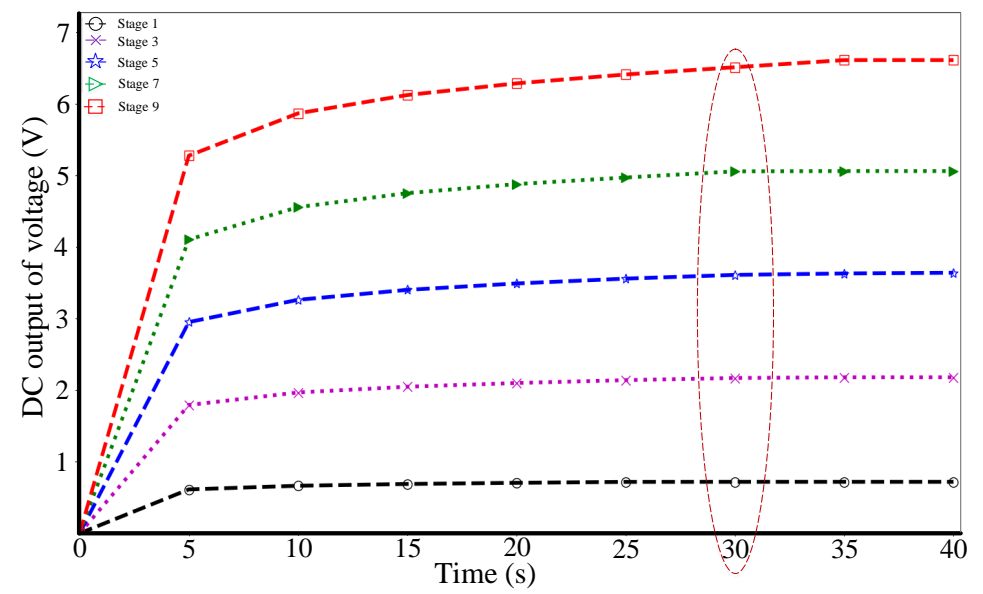

Figure 6. Output values of voltage multiplier with different stages.

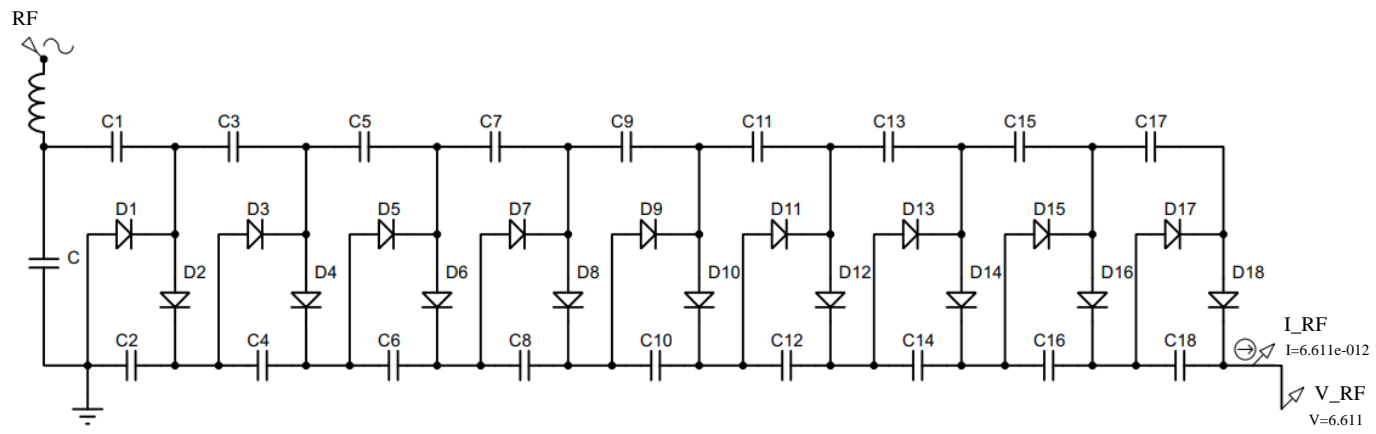

Figure 7. The scheme of the stand-alone harvesting RF energy.

\section{Charging System}

Output values of the hybrid energy system need to achieve suitable levels of both voltage and current to effectively charge the wheelchair's Li-polymer 6S1P battery. The output voltage must get approximately $22.8 \mathrm{~V}$ to satisfy input requirements of the battery. The voltage generated by the solar and RF harvesting systems are stepped up by the boost converter and VM, respectively. However, these values result to fluctuate. On the other side, the charging time for EW's battery is [31]:

$$
\text { Time }=\frac{Q_{\text {battery }}}{I}
$$

where Time is the charging time to fully charge for the battery in hours, $Q_{\text {battery }}$ is the capacity of the battery in Ampere hour (Ah), and I is the charging current in Ampere (A). Since the level of current provided by the hybrid system result to be low, this will strongly impacts on the charging time. With these perspectives, in order to address the aforementioned voltage-current issues we suppose to use the voltage-current stabilizer illustrated in Figure 8. Then, using this complete charging system, the supplying voltage will be suitable to the battery voltage, and the higher reached current reduces the charging time. 


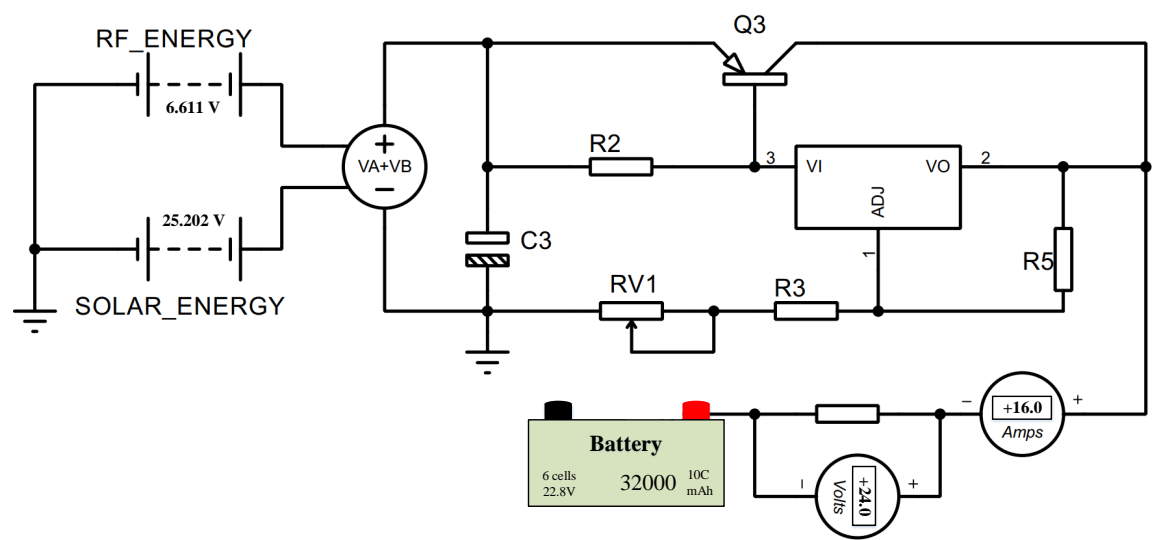

Figure 8. The charging system.

\section{Simulations and Results}

In this section, we simulate separately three scenarios, i.e., solar energy harvesting, RF energy harvesting, and hybrid solar-RF energy harvesting. For each scenario levels of harvested voltage and current will be provided.

\subsection{Stand-Alone Harvesting Solar Energy}

The solar panels are attached to top of the wheelchair, so we choose the panels which have dimensions: $121.7 \times 53.3 \times 0.2 \mathrm{~cm}$ and $1.8 \mathrm{~kg}$. With this solar area, the power able to extract from panels is $10 \mathrm{~V}$. As mentioned in Section 3.1, the harvesting energy system is equipped with MPPT method and DC-DC boost converter, which permits to harvest the highest power from the sunlight. The output values of voltage and current from the boost converter are illustrated in Figure $9 a, b$, respectively. From these figures, one can notice how the usage of the boost converter permits to step up the voltage value to $25.202 \mathrm{~V}$ with a level of provided current around $3.818 \mathrm{~A}$. However, supposing that an $32,000 \mathrm{mAh} 6 \mathrm{~S} 1 \mathrm{P}$ battery is employed, the current level is not suitable for charging it. Moreover, as mentioned before, values of current and voltage are fluctuating and then not good for charging battery.

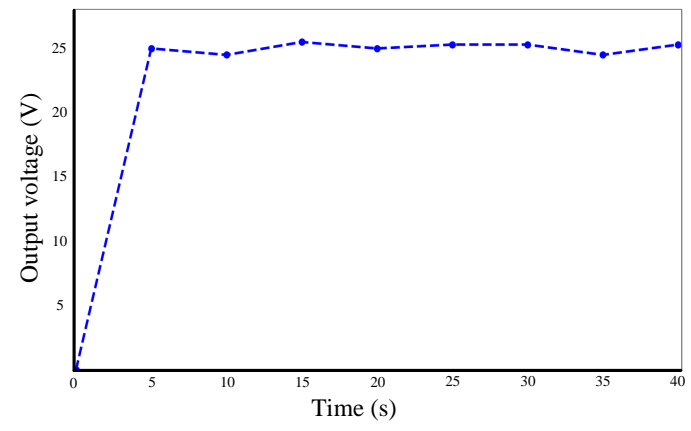

(a) Output voltage

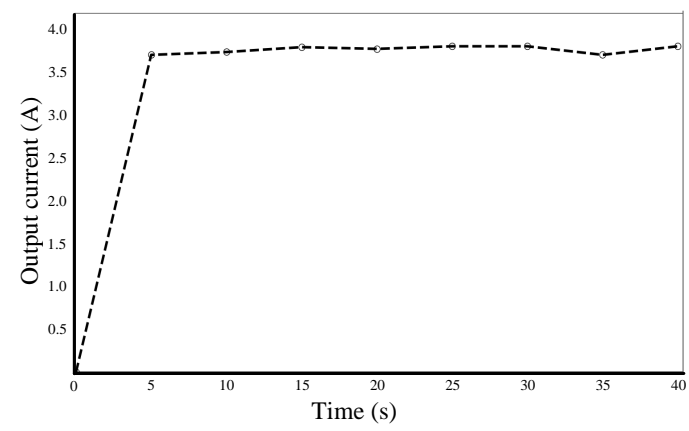

(b) Output current

Figure 9. DC output values of the harvesting solar energy.

\subsection{Stand-Alone Harvesting RF Energy}

Nine stages of VM are employed to harvest energy from RF signals. DC output values of the RF system are illustrated in Figure 10. As for the solar systems, the output voltage is at the desired output value. However, using the VM voltage and current outputs result more stable. Then, the harvesting RF system is more continuous than the solar system, but these values are not suitable to directly meet power requirements for the charging procedure. 


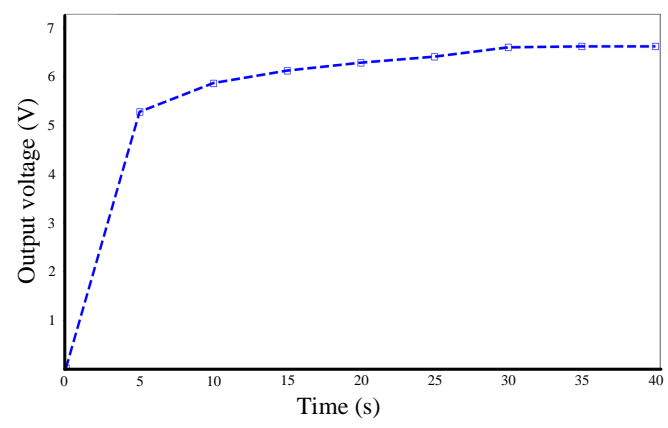

(a) Output voltage

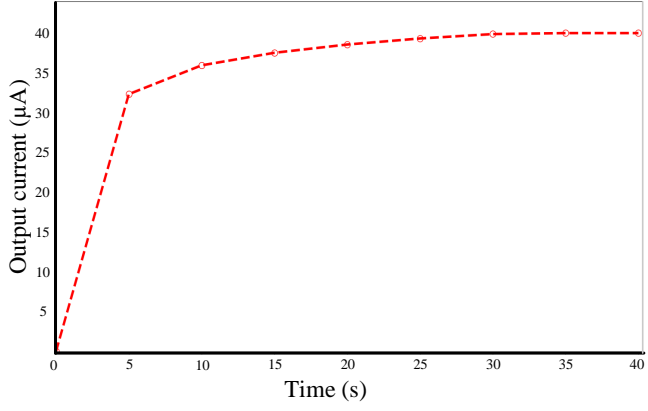

(b) Output current

Figure 10. DC output values of the harvesting RF energy.

\subsection{Hybrid Solar-RF Harvesting Energy}

From each output of the stand-alone systems, we observed that the output of each source is not able to reach the charging requirements. The hybrid method for harvesting energy from the two sources will pass through the stabilizer and boost current to increase the current and pin the voltage to a suitable value for the battery's initial requirements. The simulation results are shown in Figure 11. From this figure one can note how the proposed hybrid system is able to reach a $16.0 \mathrm{~A}$ current and the voltage is pinned at $24 \mathrm{~V}$. This value of voltage fully meets the needs of the battery and the current of 16.0 A greatly improves battery charging time according to Equation (6).

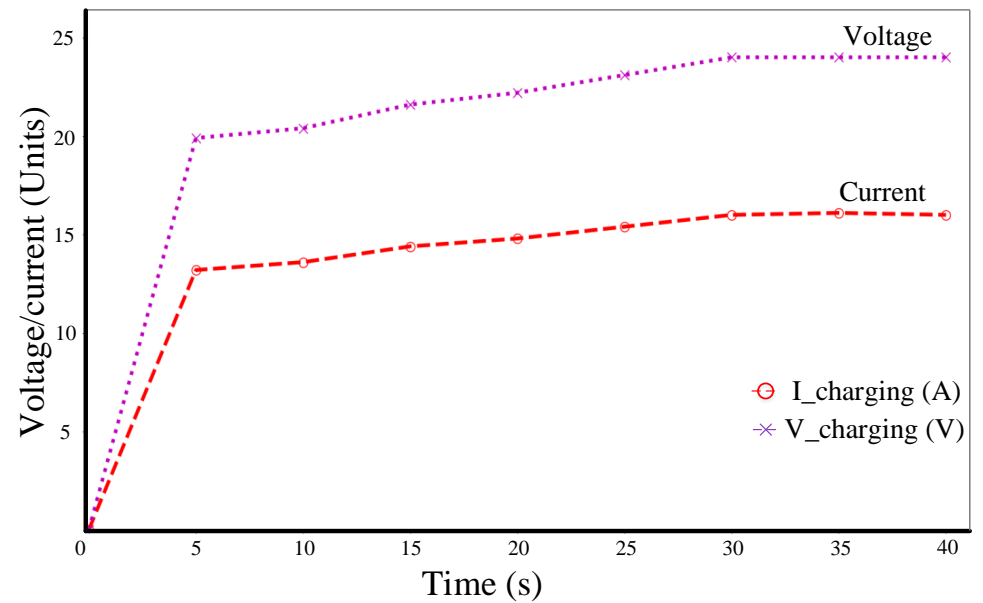

Figure 11. DC outputs of stabilizer and boost current system.

The current reaches a stable threshold of $16.0 \mathrm{~A}$ after a response time of about $30 \mathrm{~s}$. This time is acceptable because the system does not have too strict requirements in real time, and wheelchairs do not directly use the power of output of the hybrid system that is used indirectly via battery. We calculate that the estimated time to fully charge the battery is $2 \mathrm{~h}$.

\section{Conclusions and Future Work}

This paper proposes a hybrid RF and solar power system able to meet EW's battery charging requirements, providing a charging current of $16 \mathrm{~A}$ and a voltage of $24 \mathrm{~V}$. Then, this charging system, in addition to reducing battery charging time, permits improving the travel of EW's users.

Future directions of this work can be identified in the investigation and definition of methodologies aimed to improve both harvesting energy module and charging module. For example, the antenna of RF module can be optimized to properly capture high densities of frequency spectrum. 
In addition, since the MOSFET's switch of the DC-DC boost converter is a significant factor that determines the output voltage magnitude and directly causes the output fluctuation in the harvesting solar system, intelligent algorithms can be defined to achieve desired results. Finally, the charging system could be optimized in order to be dependent from the battery percentage, regulating the charge voltage and current in order to enhance the charging efficiency of the battery.

Author Contributions: Conceptualization, M.T.N. and H.T.N.; Methodology, C.V.N. and T.V.Q.; Software and Hardware Preparation, T.V.Q., A.M.L. and C.V.N.; Validation, A.M. and M.T.N.; Writing-Original Draft Preparation, all authors; Writing-Review and Editing, A.M. and M.T.N.; Supervision, M.T.N. All authors have read and agreed to the published version of the manuscript.

Funding: This research received no external funding

Acknowledgments: The authors would like to thank the Ministry of Education and Train (MOET), Viet Nam, Project B2017-TNA-30 for the support.

Conflicts of Interest: The authors declare no conflict of interest.

\section{References}

1. Faria, B.M.; Reis, L.P.; Lau, N. A Survey on Intelligent Wheelchair Prototypes and Simulators. In New Perspectives in Information Systems and Technologies; Rocha, Á., Correia, A.M., Tan, F.B., Stroetmann, K.A., Eds.; Springer International Publishing: Cham, Switzerland, 2014; Volume 1, pp. 545-557.

2. Leaman, J.; La, H.M. A Comprehensive Review of Smart Wheelchairs: Past, Present, and Future. IEEE Trans. Hum.-Mach. Syst. 2017, 47, 486-499. [CrossRef]

3. Mazumder, O.; Kundu, A.S.; Chattaraj, R.; Bhaumik, S. Holonomic wheelchair control using EMG signal and joystick interface. In Proceedings of the 2014 Recent Advances in Engineering and Computational Sciences (RAECS), Chandigarh, India, 6-8 March 2014; pp. 1-6, [CrossRef]

4. Pasteau, F.; Krupa, A.; Babel, M. Vision-based assistance for wheelchair navigation along corridors. In Proceedings of the 2014 IEEE International Conference on Robotics and Automation (ICRA), Hong Kong, China, 31 May-5 June 2014; pp. 4430-4435. [CrossRef]

5. Desmond, R.; Dickerman, M.; Fleming, J.; Sinyukov, D.; Schaufeld, J.; Padir, T. Development of modular sensors for semi-autonomous wheelchairs. In Proceedings of the 2013 IEEE Conference on Technologies for Practical Robot Applications (TePRA), Woburn, MA, USA, 22-23 April 2013; pp. 1-6. [CrossRef]

6. Sinyukov, D.; Desmond, R.; Dickerman, M.; Fleming, J.; Schaufeld, J.; Padir, T. Multi-modal control framework for a semi-autonomous wheelchair using modular sensor designs. Intell. Serv. Robot. 2014, 7, 145-155. [CrossRef]

7. Rathore, D.K.; Srivastava, P.; Pandey, S.; Jaiswal, S. A novel multipurpose smart wheelchair. In Proceedings of the 2014 IEEE Students' Conference on Electrical, Electronics and Computer Science, Bhopal, India, 1-2 March 2014; pp. 1-4. [CrossRef]

8. Wu, D.P. Electrical Wheelchair with Double Frame Structure. U.S. Patent 6,206,119, 27 March 2001.

9. Ding, D.; Parmanto, B.; Karimi, H.A.; Roongpiboonsopit, D.; Pramana, G.; Conahan, T.; Kasemsuppakorn, P. Design Considerations for a Personalized Wheelchair Navigation System. In Proceedings of the 2007 29th Annual International Conference of the IEEE Engineering in Medicine and Biology Society, Lyon, France, 23-26 August 2007; pp. 4790-4793. [CrossRef]

10. Lankenau, A.; Rofer, T. A versatile and safe mobility assistant. IEEE Robot. Autom. Mag. 2001, 8, $29-37$. [CrossRef]

11. Urbano, M.; Deti, J.F.; Nunes, U.; Zeilinger, H. Extending a smart wheelchair navigation by stress sensors. In Proceedings of the ETFA2011, Toulouse, France, 5-9 September 2011; pp. 1-4. [CrossRef]

12. Tyagi, V.; Gupta, N.K.; Tyagi, P.K. Smart wheelchair using fuzzy inference system. In Proceedings of the 2013 IEEE Global Humanitarian Technology Conference: South Asia Satellite (GHTC-SAS), Trivandrum, Kerala, India, 23-24 August 2013; pp. 175-180. [CrossRef]

13. Morère, Y.; Abdelkader, M.H.; Cosnuau, K.; Guilmois, G.; Bourhis, G. Haptic control for powered wheelchair driving assistance. IRBM 2015, 36, 293-304. [CrossRef] 
14. Nguyen, J.S.; Su, S.W.; Nguyen, H.T. Experimental study on a smart wheelchair system using a combination of stereoscopic and spherical vision. In Proceedings of the 2013 35th Annual International Conference of the IEEE Engineering in Medicine and Biology Society (EMBC), Osaka, Japan, 3-7 July 2013; pp. 4597-4600. [CrossRef]

15. Levine, S.P.; Bell, D.A.; Jaros, L.A.; Simpson, R.C.; Koren, Y.; Borenstein, J. The NavChair Assistive Wheelchair Navigation System. IEEE Trans. Rehabil. Eng. 1999, 7, 443-451. [CrossRef] [PubMed]

16. Ohno, K.; Tsubouchi, T.; Shigematsu, B.; Yuta, S. Differential GPS and odometry-based outdoor navigation of a mobile robot. Adv. Robot. 2004, 18, 611-635. [CrossRef]

17. Karakkat Narayanan, V.; Pasteau, F.; Babel, M.; Chaumette, F. Visual servoing for autonomous doorway passing in a wheelchair using a single doorpost. In Proceedings of the IEEE/RSJ IROS Workshop on Assistance and Service Robotics in a Human Environment, ASROB, Chicago, IL, USA, 1-4 September 2014.

18. Carlson, T.; del R. Millan, J. Brain-Controlled Wheelchairs: A Robotic Architecture. IEEE Robot. Autom. Mag. 2013, 20, 65-73. [CrossRef]

19. Cooper, R.A.; Vansickle, D.P.; Albright, S.J.; Stewart, K.J.; Flannery, M.; Robertson, R.N. Power wheelchair range testing and energy consumption during fatigue testing. J. Rehabil. Res. Dev. 1995, 32 3, 255-263.

20. Ramirez, D.Z.M.; Rasha, L.; Barbareschi, G.; Suzuki, T.; Caplan, I.; McKinnon, I.; Brett, D.J.; Holloway, C. Adjusted method to calculate an electric wheelchair power cycle: fuel cell implementation example. J. Energy Storage 2019, 23, 371-380. [CrossRef]

21. Takahashi, Y.; Matsuo, S.; Kawakami, K. Hybrid robotic wheelchair with photovoltanic solar cell and fuel cell. In Proceedings of the 2008 International Conference on Control, Automation and Systems, Seoul, Korea, 14-17 October 2008; pp. 1636-1640.

22. Takahashi, Y.; Matsuo, S. Running experiments of electric wheelchair powered by natural energies. In Proceedings of the 2011 IEEE International Symposium on Industrial Electronics, Gdansk, Poland, 27-30 June 2011; pp. 945-950. [CrossRef]

23. Le, A.; Truong, L.; Quyen, T.; Nguyen, C.; Nguyen, M. Wireless Power Transfer Near-field Technologies for Unmanned Aerial Vehicles (UAVs): A Review. EAI Endorsed Trans. Ind. Netw. Intell. Syst. 2020, 7, 1-18. [CrossRef]

24. Junaid, A.B.; Konoiko, A.; Zweiri, Y.; Sahinkaya, M.N.; Seneviratne, L. Autonomous wireless self-charging for multi-rotor unmanned aerial vehicles. Energies 2017, 10, 803. [CrossRef]

25. Van Nguyen, C.; Van Quyen, T.; Le, A.M.; Truong, L.H.; Nguyen, M.T. Advanced Hybrid Energy Harvesting Systems for Unmanned Aerial Vehicles (UAVs). Adv. Sci. Technol. Eng. Syst. J. 2020, 5, 34-39. [CrossRef]

26. Campi, T.; Cruciani, S.; Feliziani, M. Wireless power transfer technology applied to an autonomous electric UAV with a small secondary coil. Energies 2018, 11, 352. [CrossRef]

27. Babaa, S.E.; El Murr, G.; Mohamed, F.; Pamuri, S. Overview of boost converters for photovoltaic systems. J. Power Energy Eng. 2018, 6, 16-31. [CrossRef]

28. Hasaneen, B.; Mohammed, A.A.E. Design and simulation of DC/DC boost converter. In Proceedings of the 2008 12th International Middle-East Power System Conference, Aswan, Egypt, 12-15 March 2008; pp. 335-340.

29. Nechibvute, A.; Chawanda, A.; Taruvinga, N.; Luhanga, P. Radio frequency energy harvesting sources. Acta Electrotech. Inform. 2017, 17, 19-27. [CrossRef]

30. Curty, J.P.; Joehl, N.; Krummenacher, F.; Dehollain, C.; Declercq, M.J. A model for/spl mu/-power rectifier analysis and design. IEEE Trans. Circuits Syst. I Regul. Pap. 2005, 52, 2771-2779. [CrossRef]

31. Abdollahi, A.; Han, X.; Avvari, G.; Raghunathan, N.; Balasingam, B.; Pattipati, K.; Bar-Shalom, Y. Optimal battery charging, Part I: Minimizing time-to-charge, energy loss, and temperature rise for OCV-resistance battery model. J. Power Sources 2016, 303, 388-398. [CrossRef]

(C) 2020 by the authors. Licensee MDPI, Basel, Switzerland. This article is an open access article distributed under the terms and conditions of the Creative Commons Attribution (CC BY) license (http:/ / creativecommons.org/licenses/by/4.0/). 